\title{
Revista
}

Portuguesa

de Educação

\section{Saberes artísticos permeando a formação de pedagogos e seu eco nas Escolas}

\section{RESUMO}

No presente artigo, apresentamos uma reflexão acerca da arte como campo de saber legitimado (ou não) para a formação de professores(as) pedagogos(as) e a repercussão dessa formação em suas futuras atividades docentes com artes, nas séries iniciais da Educação Básica, e a relação dessa formação com o que determinam os documentos legais no país. Para isso, analisamos o contexto da formação inicial em Pedagogia, pontuando brevemente a evolução do campo da Arte no currículo escolar no Brasil, com foco na educação estética. Discutimos também sobre os saberes em artes que são (ou deveriam ser) proclamados e exercidos nos currículos e o que, de fato, se pratica nos currículos dos cursos de Pedagogia da Universidade Estadual do Ceará - UECE/Faculdade de Educação de Itapipoca - FACEDI - e a articulação desses currículos com as atividades de pesquisa e extensão existentes nessa instituição. Os resultados de nossas análises apontam para a compreensão de que currículo não é mera prescrição, mas um conjunto de possibilidades que nos exige considerar a diversidade presente no cotidiano escolar como elemento formativo e interventivo.

Palavras-chave: Formação Inicial; Currículo; Saberes artísticos

\section{INTRODUÇÃO}

Este artigo reflete sobre a arte como campo de saber legitimado (ou não) na universidade, particularmente no âmbito da formação inicial de pedagogos, e a repercussão dessa formação no trabalho docente em escolas de Educação Básica. No contexto da análise da formação inicial desses pedagogos, o texto focaliza especificamente a educação estética ${ }^{1}$ e os saberes em artes proclamados e exercidos no desenrolar do currículo do curso de Pedagogia, enfatizando a potência das ações integradas entre os elementos do tripé universitário - ensino, pesquisa e extensão - nesse processo educativo.

Sabendo-se que, no Brasil, o ensino de Arte é legalmente obrigatório na Educação Básica desde 1971 (Brasil, 1971), questiona-se sobre os níveis de priorização do campo de saber artístico nos currículos dos

Ana Cristina de Moraes ${ }^{i}$ Universidade Estadual do Ceará, Brasil

Georgia Tath Lima de Oliveira ${ }^{\text {ii }}$

Universidade Estadual do Ceará, Brasil

Luis Távora Furtado

Ribeiro iii

Universidade Federal do Ceará, Brasil
1. O termo Estética, dentre outras perspetivas conceituais, pode ser tomado como campo de conhecimento filosófico que elegeu a beleza como objeto; $\mathrm{A}$ Estética é também tida como a ciência do belo, onde a perceção e o julgamento sobre a beleza são focos de análises. Aesthesis, termo original advindo dos gregos, dizia respeito primordialmente à perceção e à sensação humanas. Esse conceito foi construído e modificado historicamente por diversos filósofos. A respeito dessa trajetória de construção do conceito de estética, ver Suassuna (1996). 
cursos de Pedagogia, bem como se busca explicitar os processos de consagração, ou não, do ensino de artes nesses currículos. A propósito dessa legislação, a Lei № 5.696/71 de Diretrizes e Bases para o ensino de $1^{\circ}$ e e $2^{\text {o }}$ graus, trazia o termo "Educação Artística", determinando que a mesma fosse oferecida como atividade curricular, enquanto que na Lei de Diretrizes e Bases da Educação Nacional - № 9394/96 (Brasil, 1996), atualmente em vigor, prescreve-se a obrigatoriedade do "Ensino de Arte" na Educação Básica, situando esse componente curricular como equivalente aos demais. Após diversas alterações dessa LDB ao longo do tempo, em especial no seu artigo 26, o componente Arte passa a envolver as variadas linguagens dança, teatro, música e artes visuais (Brasil, 2016) e a ser previsto, em 2017, como "estudos e práticas" e competências gerais a serem desenvolvidas no Ensino Médio.

A Universidade Estadual do Ceará (UECE) é apreendida como espaço em foco para as análises a respeito da formação docente no referido curso. A formação do pedagogo foi aqui delimitada pelo fato de ser esse profissional o que, majoritariamente, atua no ensino de Arte nas séries iniciais da Educação Básica (Educação Infantil e Ensino Fundamental até o quinto ano). Com isso, sua formação precisa estar fortemente fundamentada em bases estéticas e saberes artísticos para que o mesmo tenha possibilidades de atuar de modo mais consistente no trabalho com Arte. Sendo que, na Educação Infantil, esse profissional mobiliza "campos de experiências" das crianças permeados pelas artes ao serem mediados saberes que envolvem corpo, gestos, movimentos, cores, sons, formas e imaginação. No Ensino Fundamental, por sua vez, o pedagogo desenvolve o componente curricular Arte como sendo uma das linguagens - no conjunto que envolve também Português, Língua Estrangeira e Educação Física (Brasil, 2017). Todas essas reflexões estão guiadas pela noção de campo de Bourdieu (1983; 2004; 2006), bem como pela sua ideia de consagração de tal campo como um processo construído relacionalmente.

Para Bourdieu (2004), todo estudo ou pesquisa situa-se num campo, ao mesmo tempo científico e político. Dito isso, por que, então, estudar educação estética no âmbito universitário? Que contribuições essa reflexão pode trazer de substancial para o referido campo? Compreender os porquês dessa delimitação analítica é fundamental para se ter claro o sentido e o contexto do objeto de análise e das implicações de professores universitários e de pesquisadores em relação ao tema em foco. A autorreflexão na pesquisa é uma condição para a rutura epistemológica com os discursos instituídos, os dogmas, as teorias consagradas, como, por exemplo, a lógica de que os saberes artísticos são secundários na educação formal. Estes se constituem em meio às relações de poder que permeiam a sociedade e se dispõem a determinar escolhas, comportamentos, pensamentos e modos de agir dos agentes.

Nessa perspetiva, a problematização contida neste texto refere-se aos aspetos curriculares vinculados aos saberes em artes prescritos e exercidos na UECE no âmbito do tripé universitário, mais particularmente nos currículos dos cursos de Pedagogia, distribuídos nas sete unidades de ensino dessa instituição, que oferecem o referido curso presencialmente ${ }^{2}$.
2. Além destes, a UECE oferece mais dois cursos de Pedagogia à distância, pela Universidade Aberta do Brasil (UAB) e pelo Plano Nacional de Formação de Professores (PARFOR).

\section{ENQUADRAMENTO TEÓRICO}




\subsection{O CAMPO DA ARTE NA FORMAÇÃO DO PEDAGOGO E SEU ENSINO NA ESCOLA}

"E existe formação estética (através da arte) na universidade"? Foi com esse questionamento que, em tom de ironia, um colega, também professor da universidade na qual trabalhamos, nos surpreendeu ao ouvir-nos falar a respeito de um estudo desenvolvido sobre o assunto. Enunciado que, tanto revelou uma denúncia da suposta ausência desse saber na universidade (fora dos cursos específicos em arte), como nos instigou o desejo de construir outra realidade, na qual o agente observador não tenha a necessidade de fazer perguntas dessa natureza. Utopia? Não só isso, mas impulso de realização. Se a educação estética pela arte nos exige uma razão prática, torna-se necessário produzi-la. Nesse sentido, pensá-la é (também e juntamente) fazê-la. E por que não promover essa educação estética dentro da universidade em seus diversos espaços? Por que não possibilitar seu trânsito entre o ensino, a pesquisa e a extensão como canais de circulação do "sangue" estético-formativo nas veias das pessoas?

A arte, esse campo de saber e modo de expressão humana, manifesta-se em atos criativos de caráter estético e se constrói pela dilatação da perceção e pelo exercício da imaginação expresso em objetos artísticos. É ainda manifestação de um desejo de aperfeiçoamento e de beleza através desses objetos. Arte é, pois, uma composição estética que pode se configurar através das linguagens musical, teatral, dançante, literária, pictórica, visual, cinematográfica.

O campo artístico delineia-se, social e historicamente, considerando como campo esse "[...] universo no qual estão inseridos os agentes e as instituições que produzem, reproduzem ou difundem a arte, a literatura ou a ciência. Esse universo é um mundo social como os outros, mas que obedece a leis sociais mais ou menos específicas" (Bourdieu, 2004, p. 20).

Esse campo constitui-se um dos mais privilegiados no que diz respeito ao favorecimento de experimentações estéticas, por ter como matéria-prima a dimensão criativa intimamente aliada à dimensão lúdica das pessoas. A produção, a análise e a fruição artísticas (Barbosa, 2014) permitem a expansão imaginativa materializada num objeto ou obra de arte e, nesse decurso, desenvolve-se o senso estético em meio a um processo educativo contínuo.

A educação estética caracteriza-se, assim, como um processo de ampliação percetiva das pessoas sobre as coisas e sobre si mesmas. É um trabalho de aperfeiçoamento da sensibilidade em direção à beleza. Refere-se também a um processo de expansão do repertório pessoal através de experiências estéticas, podendo ter a arte como canal para tal expansão. Duarte-Junior (2010) expõe uma interessante explicação sobre a referida noção:

[...] deve-se entender a educação estética exatamente como o processo de auxiliar o desenvolvimento da percepção poética. Um processo pelo qual se busca levar os educandos a desenvolver em si o estado poético, a conseguir equilibrar as duas formas fundamentais de relacionamento humano com a realidade: a estética (ou poética) e a prática (ou prosaica). Para tal trabalho, as artes são, com efeito, convocadas como instrumento educacional; porém, a educação estética não se restringe ao seu emprego. Tudo 
aquilo que ajude a refinar nossa sensibilidade, a acurar nossos sentidos, pode se tornar parceiro em tal jornada [...]. (p. 74)

0 autor faz referência a dois modos de relacionamento humano com o mundo: o poético e o prosaico. Estes são elementos que contribuem para a ampliação da perceção humana nos aspetos estético e prático, respetivamente (Ibidem, 2010).

Aprofundar o campo de saber estético no âmbito da formação de pedagogos, torna-se, pois, imprescindível à dilatação da perceção e da sensibilidade humanas. Essa formação não é importante (apenas) pelas crescentes demandas de suprir a carência por professores de Arte nas escolas, mas transcende essa questão, propondo a ampliação do horizonte formativo desse profissional.

Essa formação pode se concretizar numa teia na qual os trabalhos de alguns professores, dotados de experiências formativas estéticas, tenderão a repercutir nas vidas de seus educandos, quando da atuação destes na Educação Básica, possibilitando o crescimento de espaços de experimentação estética, seja ela por via da apreciação, da criação ou da análise de obras artísticas (Barbosa, 1985, 2014). Essa perspetiva se direciona a uma gradual transformação cultural, ampliando, assim, o repertório das pessoas e criando um estado social estético, para utilizar aqui os termos de Schiller (1991) e fazer referência ao seu grandioso (e poético) desejo de ver a humanidade assim constituída.

Essa transformação cultural almejada, requer permanente e rigoroso trabalho educativo, tanto dos próprios professores como, por consequência, das crianças e adolescentes. Educação apreendida como processo de construção, de apropriação e de reprodução de conhecimentos produzidos em meio às relações sociais pedagógicas envolvendo, concomitantemente, o ensino e a aprendizagem. Compreendida nesse prisma, a educação constitui-se como um exercício histórico de mobilização de saberes, pois as ações educativas se exercem em um continuum no decorrer das vivências cotidianas dos indivíduos. Esta também pode se realizar em diversos espaços e de diversas formas, não somente em instituições formais de ensino, apesar de que são nessas instituições que as intenções pedagógicas são mais explícitas e direcionadoras de processos educativos. Bourdieu define ação educativa como socialização, elemento que ajuda a construir os processos transformadores das pessoas, podendo ser considerada como mera transmissão de saber, apesar de que as escolas, muitas vezes, exercem ações de legitimação de valores hegemônicos, em uma lógica de transmissão de saberes homogêneos, deixando de lado as diferenças de gênero, classe social, etnia etc.

No caso particular da Arte, que compõe o campo de saber que aqui nos interessa diretamente, esta é tanto disciplina curricular em diversos currículos de Pedagogia (que assume a denominação Arte-educação em muitos currículos de formação de pedagogos), como é componente curricular obrigatório nas escolas, seja ele oferecido em forma de disciplina ou em forma de outras atividades/projetos escolares. Arte-educação, essa educação através da arte, é um termo controverso e que criou várias vertentes de conceituação e de intervenções ao longo da história ${ }^{3}$. Refere-se, de modo geral, às ações educativas para o desenvolvimento do senso estético e para a apropriação de saberes artísticos, envolvendo a apreciação, a criação e a análise de obras de arte. Diz respeito ainda às ações educativas que
3. Um primeiro movimento em defesa da arte-educação desenvolve-se a partir das contribuições do inglês Herbert Read já na década de 1940. Por influência desse filósofo, na década de 1980 , um movimento norte-americano (através do Getty Education Institute) instituiu a arte-educação como disciplina, ficando conhecida como Discipline Based Art Education (DBAE). A DBAE é, para seus precursores, constituída de diversos saberes a serem acionados articuladamente entre si: a produção artística, a história da arte, a crítica da arte e a estética. 
canalizam processos de ensino de diferentes saberes através da arte. Apreender uma ou mais conceções de arte-educação requer uma assimilação histórica de construção desse conceito e de suas experimentações formativas cotidianas em espaços educativos diversos, o que não daria para abranger, discursivamente, nos limites deste texto ${ }^{4}$. É fundamental enfatizarmos que essa terminologia Arte-educação é comumente utilizada no âmbito dos currículos de formação docente, em especial de pedagogos e que, em geral, nas legislações específicas e na Educação Básica, o termo Arte é o que intitula o campo de saber artístico como componente curricular.

Para uma explicitação de ideias a esse respeito, apresentamos duas perspetivas com o intuito de se compreender o campo da Arte-educação. A primeira, apontada por Coelho (2012), explica que:

Há, no campo da arte-educação, duas filosofias predominantes. Uma se apresenta como "educação para a arte", orientada para o produto (no ensino superior, voltada para as "belas artes") e outra, a "educação através da arte", centrada na criança ou no estudante (e que no ensino superior tem por foco programas de formação de professores). Os programas de arte-educação centrados na criança não menosprezam as artes, mas encaram-nas em sua relação com a criança e no conjunto do currículo escolar. (p. 67)

No sentido da Arte-educação como potencializadora da formação estética, Duarte-Junior (2011) justifica a necessidade e relevância desse campo de conhecimento da seguinte maneira:

A finalidade da arte-educação deve ser, sempre, o desenvolvimento de uma consciência estética. E consciência estética, aí, significa muito mais do que a simples apreciação da arte. Ela compreende justamente uma atitude mais harmoniosa e equilibrada perante o mundo, em que os sentimentos, a imaginação e a razão se integram; em que os sentidos e valores dados à vida são assumidos no agir cotidiano. (p. 73)

Nesse argumento, percebe-se a grandiosidade formativa que há numa perspetiva de se abraçar um processo de educação estética, tanto na formação de professores como de crianças e adolescentes. Duarte-Junior (2011) reforça sua defesa da Arte-educação como premissa essencial para a formação humana integral:

[...] a revalorização da beleza e da imaginação encontrou, na arte e no brinquedo, dois aliados poderosos. Por que não se educar as novas gerações evitando-se os erros que viemos cometendo? Por que não se entender a educação, ela mesma, como algo lúdico e estético? Por que, em vez de fundá-la na transmissão de conhecimentos apenas racionais, não fundá-la na criação ${ }^{5}$ de sentidos considerando-se a situação existencial concreta dos educandos? Por que não uma arte-educação ${ }^{6}$ ? (p. 65)

Historicamente, observa-se certa desvalorização das artes nos currículos escolares e universitários, no âmbito da formação de professores, tanto pela pouca oferta de cursos específicos em Arte, como pela quase
4. Sobre a trajetória histórica da arte-educação, Barbosa (1985) tece um interessante traçado, especificamente no Brasil, a partir do surto industrial no final do século XIX.
5. Itálico nosso.
6. Itálico nosso. 
ausência desse campo de conhecimento nos currículos de outros cursos, particularmente das licenciaturas. Tal campo vem, só muito recentemente, sendo incorporado às discussões e pautas de reivindicações, compondo mais intensamente o atual cenário de debates em eventos nacionais diversos ${ }^{7}$.

Em meio a tudo isso, esse campo de saber no currículo é legalmente obrigatório, apesar de não estar especificado na atual Lei de Diretrizes e Bases, № 9394/96 (Brasil, 1996), pois a obrigatoriedade precisaria estar prescrita nos nove anos do Ensino Fundamental e nos três anos do Ensino Médio, para que abrangesse toda a Educação Básica. 0 texto legal diz apenas que deve ser oferecida nessa etapa de ensino.

Ressalte-se ainda que o atual documento curricular em vigência no Brasil - a Base Nacional Comum Curricular - BNCC (Brasil, 2018) esvazia ainda mais o papel da arte nos currículos da Educação Básica. Com isso, muitos sistemas de ensino implementam a referida lei apenas no limite da obrigatoriedade, não priorizando ou ampliando essa área de conhecimento. Além desse fator, em geral, nas escolas observadas no estado do Ceará, o que também representa uma tendência nacional, o tempo curricular destinado semanalmente a essa disciplina é muito restrito, aliado à falta de professores devidamente qualificados e em número insuficiente para atender à demanda ${ }^{8}$.

De acordo com dados do Núcleo de Assessoria Pedagógica da Secretaria de Educação de determinado município cearense ${ }^{9}$, na programação curricular de cada escola, no ano de $2009^{10}$, o ensino de Arte era oferecido do $1^{\mathrm{o}}$ ao $9^{\mathrm{o}}$ ano como disciplina em apenas uma aula semanal, com 50 minutos de duração. Essa disciplina equipara-se à de Educação Física ou recreação (do $1^{\mathrm{o}}$ ao $5^{\mathrm{o}}$ ano) em quantidade de horas/semana, sendo esse fato um possível indício da falta de prioridade e da pouca importância que lhe é atribuída no currículo das escolas municipais, evidenciando que essa tendência vem sendo mantida ao longo dos anos.

As disciplinas acima citadas, Arte e Educação Física, historicamente, situam-se num lugar marginal nos currículos escolares. Isso denuncia, objetivamente, o campo das relações de força em que os diferentes saberes curriculares se movem, pois, por exemplo, a matemática e o português são tidos como os "mais" importantes campos de conhecimentos e "precisam" ocupar o maior espaço possível nos currículos escolares. Ora, na sociedade "da informação", da "racionalidade", da "tecnologia", marcada pela lógica tecnicista, produtivista e consumista, quem vai questionar isso? Essa "verdade" foi historicamente consagrada no âmbito das relações societárias de poder, apesar de que, nos últimos anos, o movimento de educadores, especificamente de professores de Arte e de artistas, vem promovendo debates em favor da ampliação da arte como conhecimento curricular nas escolas. E esse movimento vem gerando frutos importantes como o crescimento de cursos de licenciaturas em diferentes linguagens artísticas no Brasil $^{11}$, além de uma maior atenção dada à arte na escola.

Em 2008, por exemplo, foi instituída a Lei № 11.769/08 (Brasil, 2008) que torna a música conteúdo obrigatório nos currículos escolares. Sendo que em 2016 nova Lei (№ 13.278/2016) amplia as linguagens artísticas, tornando obrigatórias na escola a dança, o teatro, a música e as artes visuais. Isso, por conseguinte, vem gerando uma demanda por professores que dominem essas linguagens artísticas para atuarem na Educação Básica, o que é algo positivo, posto que esforços no campo das políticas educacionais estão sendo mobilizados para a efetivação dessa lei.
7. Dentre esses eventos nacionais, podemos citar como encontros de maior relevância em matéria de repercussão das discussões sobre Arte-educação: a Associação Nacional de PósGraduação e Pesquisa em Educação (ANPed) (GT 24 Educação e Arte); a Federação de Arte-Educadores do Brasil (FAEB); a Associação Brasileira de Pesquisa e Pós-Graduação em Artes Cênicas (ABRACE); a Associação Brasileira de Educação Musical (ABEM).

8. Em estudo feito entre 2007 e 2009, a respeito do perfil de formação dos professores de Arte das escolas do município de Itapipoca-CE, com 116.065 habitantes (Instituto Brasileiro de Geografia e Estatística [IBGE], 2010), a grande maioria desses professores não possui formação específica em artes. Dentre dez professores respondentes, apenas um deles possuía uma especialização em arte-educação. Oito deles eram graduados em pedagogia.

9. Itapipoca-CE, município do Litoral Oeste do estado do Ceará.

10. Dados produzidos por conta de pesquisa publicada: Moraes (2010). 
Com isso, mais uma vez nos remetemos a Bourdieu (2004, pp. 22-23) quando este ressalta que todo campo "é um campo de forças e um campo de lutas", seja para conservar ou para transformar tal campo de forças.

Desse modo, o campo do ensino de Arte é bastante representativo desse "campo de forças e de lutas", traduzindo-se em espaço de contínua construção política, artística e científica.

O campo artístico, - e também o seu ensino -, segundo o próprio autor (Ibidem), além de possuir uma autonomia relativa (característica própria de cada campo), se constrói pelo fato de haver artistas e suas obras objetivamente situadas e inter-relacionadas, ou seja:

A autonomia relativa do campo artístico como espaço de relações objectivas em referência aos quais se acha objectivamente definida a relação entre cada agente e a sua própria obra, passada ou presente, é o que confere à história da arte a sua autonomia relativa e, portanto, a sua lógica original. Para explicar o facto de a arte parecer encontrar nela própria o princípio e a norma de sua transformação - como se a história estivesse no interior do sistema e como se o devir das formas de representação ou de expressão nada mais fizesse além de exprimir a lógica interna do sistema não há necessidade de hipostasiar, como frequentemente se faz, as leis desta evolução; se existe uma história propriamente artística, é, além do mais, porque os artistas e os seus produtos se acham objectivamente situados, pela sua pertença ao campo artístico, em relação aos outros artistas e aos seus produtos e porque as rupturas mais propriamente estéticas com uma tradição artística tem [sic] sempre algo que ver com a posição relativa, naquele campo, dos que defendem esta tradição e dos que se esforçam por quebrá-la. (Bourdieu, Ibidem, p. 73)

Para Bourdieu, os agentes, ao mesmo tempo em que são produzidos num contexto sócio histórico, também produzem esse contexto; eles exercem sua capacidade de inventar, de criar, em meio à sua autonomia relativa. Do mesmo modo, o campo da Arte-educação, seja na escola, seja na universidade, se constrói pelo fato de haver arte-educadores situados e inter-relacionados nesse dado contexto.

\subsection{O ESPAÇO DAS ARTES NOS CURRÍCULOS E A POTÊNCIA DO TRIPÉ UNIVERSITÁRIO PARA A AMPLIAÇÃO DESSE ESPAÇO}

Currículo é linguagem, assim ele também é elemento que produz cultura, não apenas a reproduz e, nessa perspetiva, defende-se que é preciso se evitar determinismos.

0 entendimento do currículo como prática de significação, como criação ou enunciação de sentidos, torna inócua distinções como currículo formal, vivido, oculto. Qualquer manifestação do currículo, qualquer episódio curricular, é a mesma coisa: a produção de sentidos. Seja escrito, falado, velado, o currículo é um texto que tenta direcionar o 'leitor', mas que o faz apenas parcialmente (Lopes \& Macedo, 2011).

A elaboração de um currículo, seja ele de cursos de graduação, seja de Educação Básica, compõe-se de uma dinâmica processual de negociações,
11. No caso do Ceará, Estado do Nordeste com uma população de 8.448 .055 habitantes (IBGE, 2010), distribuídos em seus 184 municípios, atualmente há 15 cursos de Artes, entre licenciaturas e bacharelados, divididos entre sete universidades (05 públicas e 02 particulares) em três cidades cearenses (mas concentrados principalmente na Capital) com um total de seis linguagens artísticas contempladas, sendo o mais antigo deles o de Música da UECE, criado em 1977.

Alguns desses cursos foram criados muito recentemente, de 2008 até hoje, devido, principalmente à promulgação da Lei No 11.769/08, que torna obrigatória a música como saber escolar (Brasil, 2008) e também pelas exigências de arte-educadores pelo cumprimento da obrigatoriedade das Artes nos currículos escolares. http://www.opovo.com.br/app/o povo/vidaearte/2013/04/09/not iciasjornalvidaearte,3035407/ar te-em-formacao- um-roteirodos-cursos-de-graduacao-emarte-no-ceara.shtml. 
agenciamentos e, consequentemente, de relações de poder. É uma produção cultural por inserir-se na luta

[...] pelos diferentes significados que conferimos ao mundo. 0 currículo não é um produto de uma luta fora da escola para significar o conhecimento legítimo, não é uma parte legitimada da cultura que é transportada para a escola, mas é a própria luta pela produção do significado. (Lopes \& Macedo, 2011, p. 93)

O currículo, como produção cultural, é um dispositivo produtor de sentidos pela ação e interação dos agentes.

As atuais legislações educacionais ${ }^{12}$ instituem uma multiplicidade de componentes curriculares envolvendo o ensino, a pesquisa e a extensão no âmbito do Ensino Superior. Em tais legislações, aponta-se a necessidade da indissociabilidade entre essas três instâncias como ação imprescindível ao processo de formação profissional, pois, esse tripé universitário, quando bem articulado,

[...] conduz a mudanças significativas nos processos de ensino e de aprendizagem, fundamentando didática e pedagogicamente a formação profissional, e estudantes e professores constituem-se, efetivamente, em sujeitos do ato de aprender, de ensinar e de formar profissionais e cidadãos [...] A pesquisa e a extensão, em interação com o ensino, com a universidade e com a sociedade, possibilitam a relação entre teoria e prática, democratização do saber acadêmico e o retorno desse saber à universidade, testado e reelaborado. (Dias, 2009, pp. 39-40)

A extensão e a pesquisa universitárias tendem a mobilizar saberes e aprendizagens diversas e até diferenciadas do que comumente é feito nas atividades de ensino em sala de aula, pois nelas há uma inclinação maior para as realizações de intercâmbio com outros agentes e instituições fora da universidade, bem como para a criação e a formação artística, política etc. Com isso, vê-se o quanto as ações integradas entre ensino, pesquisa e extensão são essenciais, pois ampliam as possibilidades formativas dos estudantes e tendem, assim, a gerar um processo de educação integral, o que abrange também a educação estética. E, para os pedagogos, essa educação integral precisa ser assegurada, pois estes irão exercer ações pedagógicas diversas e precisam adquirir um amplo e denso repertório de saberes.

Os saberes que abrangem uma formação estética de pedagogos estão prescritos nas citadas Diretrizes Curriculares Nacionais (Brasil, 2006; 2015) e isso representa uma possibilidade interessante, do ponto de vista da existência de um aparato legal que estimule a composição dos currículos de formação de pedagogos nessa direção, apesar de que uma prescrição não tenha um "poder mágico" de efetivação de uma proposta formativa, se diferentes agentes não tomarem a iniciativa de implementá-la.

Dentre as referidas legislações que tratam mais diretamente da inserção das artes nos currículos escolares, realçamos que a mais recente é a Lei № 13.278/2016 (Brasil, 2016), que altera o § 6을 do Art. 26 da LDB 9394/96, referente ao ensino da Arte envolvendo todas as linguagens (teatro, dança, artes visuais e música) ${ }^{13}$. Atualmente, temos também a Base Nacional
12. Brasil (1988). Constituição da República Federativa do Brasil, de 05 de outubro de 1988. Brasília: Casa Civil; Brasil (1996). Lei de Diretrizes e Bases da Educação Nacional, Lei no 9394/96. Brasília: Ministério da Educação; Brasil (1997). Parecer $n^{\circ} 776$, de 03 de dezembro de 1997. Brasília: Conselho Nacional de Educação/Câmara de Educação Superior; Brasil (2001). Plano Nacional de Educação, Lei ${ }^{\circ}$ 10172, de 09 de janeiro de 2001. Brasília: Ministério da Educação; Brasil (2006). Diretrizes Curriculares Nacionais para o Curso de Graduação em Pedagogia. Brasília: Conselho Nacional de Educação/Conselho Pleno; Brasil (2015). Diretrizes Curriculares Nacionais para a Formação em Nível Superior (cursos de licenciatura, cursos de formação pedagógica para graduados e cursos de segunda graduação) e Para a Formação Continuada. Brasília: Conselho Nacional de Educação/Conselho Pleno.

13. Art. 26. - § $2^{\circ} \mathrm{O}$ ensino da arte constituirá componente curricular obrigatório, nos diversos níveis da educação básica, de forma a promover o desenvolvimento cultural dos alunos (Brasil, 1996). 
Comum Curricular - BNCC (Brasil, 2018), que assinala saberes em artes no currículo da Educação Básica.

Nessas legislações, infelizmente, por não estar especificada a possibilidade de ampliação e aprofundamento do ensino de Arte nas escolas em todas as etapas e anos de ensino, isso as deixa livres para legitimar a falta de prioridade sobre esse campo de conhecimento na Educação Básica. E, ante essa falta de prioridade, cabe questionar sobre o lugar das artes no currículo escolar, bem como no currículo do Curso de Pedagogia: "[...] de onde vem o poder de consagrar [...]? Quem atribui importância ou 'reputação' a elas"? (Bourdieu, 2006, pp. 23-25).

Temos dito que qualquer organização curricular é permeada de relações de poder na definição de seus saberes. E o que faz as reputações é [...] o campo da produção como sistema das relações objetivas entre esses agentes ou instituições e espaço das lutas pelo monopólio do poder de consagração em que, continuamente, se engendram o valor das obras e a crença neste valor (Ibidem).

As relações de poder que permeiam a elaboração curricular nas escolas e nas universidades, geralmente, impõem ao saber artístico um lugar de pouco destaque ou de desprestígio (como já exposto), salvo em momentos contingenciais, como datas comemorativas ou alguns eventos institucionais como forma de "enfeitar" ou "alegrar" o evento: "Todo conhecimento depende da significação e esta, por sua vez, depende de relações de poder. Não há conhecimento fora desses processos" (Silva, 2007, p. 149). Prova concreta disso é o já observado tempo semanal reduzido, destinado ao ensino de artes na carga horária dos estudantes da Educação Básica ${ }^{14}$.

Já na Universidade, a instituição da disciplina intitulada Arteeducação, por exemplo, nos currículos dos cursos de Pedagogia da UECE, compôs um recente jogo de forças que envolveu a necessidade de apropriação das determinações legais, postas nas atuais Diretrizes Nacionais para os Cursos de Pedagogia (Brasil, 2006). Aqui, leva-se em consideração a problematização feita por Ferraço (2008), na qual destaca que uma prescrição curricular não quer dizer, necessariamente, que a mesma esteja sendo concreta e cotidianamente efetivada. Os componentes curriculares elencados nos cursos de Pedagogia da $\mathrm{UECE}^{15}$, expõem intenções de educação estética, apesar de que, além do fato de existirem algumas prescrições curriculares - sejam obrigatórias ou optativas - as mesmas não garantem uma ação efetiva e contínua de priorização do saber estético-artístico na formação dos pedagogos, se os responsáveis por essa formação (instituições e professores formadores) não se dispuserem a valorizar e exercer efetivamente tal campo de saber.

\subsection{ARTE A PASSOS LARGOS NO EXERCÍCIO DO TRIPÉ UNIVERSITÁRIO}

Exercer arte no currículo de Pedagogia requer ousadia, manifesta num esforço de criação de um projeto pedagógico que a apreenda como um saber dotado de forte potência para desenvolver-se transversalmente, tanto no âmbito dos saberes disciplinares, como no processo de integração entre ensino, pesquisa e extensão. O currículo desse curso tem (em âmbito nacional) uma especificidade que alguns chamam de generalista e isso tanto pode ampliar as possibilidades formativas do pedagogo como pode tender para a superficialidade. Entretanto, quando um currículo de formação de professores se propõe a integrar ensino, pesquisa e extensão, as
14. Em encontro sobre Ensino Superior em Itapipoca-CE, ocorrido dia 10 de abr. de 2013, a postura do representante do $2^{\circ}$ CREDE a respeito do ensino de Arte era que, ao mesmo tempo em que ele mostrou dados alarmantes sobre as Autorizações Temporárias de professores para dar aula não sendo dessa área de conhecimento - onde as artes ocupam o $1^{\circ}$ lugar - ele, por outro lado, não considerou importante exigir do governo estadual a abertura de uma licenciatura em artes na cidade. Vejam, nos dados de 2012, o descaso a partir dos dados de Autorizações Temporárias para os professores ministrarem aulas em outras disciplinas que não a de sua formação: Arte e educação $=491 ;$ Matemática $=$ 307; Inglês = 302; Geografia = 273; Língua portuguesa $=244$. Segundo dados de 2015, esses números permanecem quase os mesmos, mantendo-se essa ordem das áreas de conhecimento. Paradoxalmente, os cursos considerados importantes para abrir turma no município foram: Letras, Matemática e Geografia. Ou seja, um curso de Arte para a formação de professores não foi considerado prioritário, apesar dos dados. Esse problema também está intimamente associado à ausência de políticas públicas de formação de professores na área de Arte.

15. A respeito desse levantamento sobre os currículos dos cursos de Pedagogia da UECE, ver o estudo publicado: Moraes (2016). 
possibilidades de garantia de uma aprendizagem interdisciplinar e mais consistente aumentam, pois há uma mobilização de agentes e de práticas no exercício cotidiano desse currículo. Nessa mobilização, a parceria entre professores para o fomento e a execução de projetos interligados é essencial. Estimular estudos e experimentações em arte, ampliar os espaços de diálogos e manter certa insistência na defesa das artes no espaço universitário é também fundamental para fortalecer e aprofundar esse campo de conhecimento.

Dentro dessa perspetiva para a formação dos pedagogos, as universidades poderão garantir uma base de fundamentação artística para esses futuros profissionais fazendo valer suas prescrições legais ${ }^{16}$, como o princípio de indissociabilidade entre ensino, pesquisa e extensão. Concretamente, como viabilizar esse princípio? Em que ações, tempos e espaços o tripé universitário poderia se sustentar para se desenvolver no cotidiano da instituição? Há recursos humanos e financeiros suficientes para tal investida? Sabe-se que, no plano das ideias (Mairinque, 2003), tal princípio de indissociabilidade é muito complexo e potente; no plano concreto (Mairinque, 2003), do dia a dia da universidade, essa proposta pode ser realizada na articulação entre, por exemplo, professores e agentes externos à comunidade para a realização de ações pedagógicas em conjunto; entre professores coordenadores de grupos de pesquisa e de grupos de extensão, para favorecer a troca de saberes e o intercâmbio entre os estudantes componentes de cada um desses grupos; dentre tantas outras atividades possíveis de serem criativamente elaboradas e executadas.

0 princípio da indissociabilidade entre ensino, pesquisa e extensão reflete um conceito de qualidade do trabalho acadêmico que favorece a aproximação entre universidade e sociedade, a autorreflexão crítica, a emancipação teórica e prática dos estudantes e o significado social do trabalho acadêmico.

A concretização desse princípio, supõe a realização de projetos coletivos de trabalho que se referenciem no planejamento de ações institucionais e nos interesses da maioria da sociedade (Associação Nacional dos Docentes do Ensino Superior [ANDES], 2013).

Compromisso cotidiano, investimentos na universidade pública e diálogo entre diferentes agentes que compõem a universidade são exigências fundamentais para a viabilização de ações integradas entre o ensino, a pesquisa e a extensão, sob pena de continuarmos com a histórica predominância do ensino como praticamente a única instância de fomento à formação profissional e pessoal de professores. Nessa direção, concordamos que

[...] compreender as atividades de extensão e de pesquisa como expedientes vitais aos processos de ensino e de aprendizagem na graduação requer proposta de formação fortemente articulada à vivência do real e imersa na própria realidade, fundada em uma relação dialética entre teoria e prática. (Dias, 2009, p. 06)

É com essa orientação que juntamos esforços para desenvolver ações pedagógicas no âmbito do curso de Pedagogia da UECE/Faculdade de Educação de Itapipoca (FACEDI), envolvendo os três elementos do tripé universitário. Por exemplo, em uma ocasião na qual ministramos a disciplina de Arte-educação, havíamos planejado algumas das aulas em forma de aula-
16. Brasil (1988).

Constituição da República Federativa do Brasil, de 05 de outubro de 1988. Brasília: Casa Civil; Brasil (1996). Lei de Diretrizes e Bases da Educação Nacional, Lei No 9394/96. Brasília: Ministério da Educação. 
oficina, nas quais um grupo artístico - do Projeto de Extensão Núcleo de Artes Cênicas (NACE) da FACEDI - foi convidado a fazer parte; ou ainda, quando organizamos eventos anuais - como o "Contos e Cantos ao Redor do Fogo" 17, por exemplo - e todos os estudantes e professores foram e são convidados tanto para coordenar atividades como para elaborar produções artísticas para expor no dia do evento.

No referente à articulação entre ensino e pesquisa, podemos citar o componente curricular denominado "Pesquisa e Prática Pedagógica (PPP)", que é uma disciplina oferecida semestralmente com a intenção de articular saberes de diferentes disciplinas durante o semestre e também de envolver práticas de pesquisas empíricas sobre temas relacionados ao campo da Pedagogia.

Todas essas propostas estão em execução, não sem dificuldades, pois a lógica curricular posta hoje, principalmente a partir das Diretrizes Curriculares para os Cursos de Pedagogia (Brasil, 2006), requer uma atitude interdisciplinar, além de abertura ao diálogo e também muita criatividade e disposição para o trabalho coletivo. A quase ausência desse perfil no corpo de professores representa, pois, uma barreira para a realização dessas propostas.

No entanto, é importante destacar que as intenções de integração existem, ao menos na disposição de alguns professores e estudantes, para fazer valer o princípio da indissociabilidade dos elementos do tripé universitário. E é com esse esforço de criar ações que integrem o ensino, a pesquisa e a extensão universitária que buscamos exercer nosso trabalho pedagógico cotidianamente, tentando ainda contagiar mais pessoas nesse empreendimento educativo.

\section{CONSIDERAÇÕES FINAIS}

Problematizar sobre a formação estética e artística na universidade é refletir sobre a relevância desses campos de conhecimento no currículo e também perceber as relações de poder que permeiam suas afirmações ou negações nas instituições educativas.

Dada a diversidade de agentes e de contextos, é importante ter em vista que não há projeto curricular emancipatório único. Com isso, concordamos com Lopes e Macedo (2011, p. 183) quando afirmam que uma proposta de currículo, não é algo dado, mas algo que requer construção coletiva, pois ela não está pronta, mas “[... É sempre uma proposta contingencialmente construída, em lutas culturais e políticas, nas quais a diferença e os processos de identificação devem ser entendidos como centrais".

Acreditamos que currículo não é mera prescrição, na qual a própria formação de professores, muitas vezes, é permeada por essa lógica prescritiva, com formato de receita a ser seguida. Concordamos, pois, com Ferraço (2008), que expõe a necessidade de considerarmos a diversidade de possibilidades presentes no cotidiano escolar como elementos formativos e interventivos. Com essa perspetiva, o mesmo sugere que focalizemos os agentes que compõem a instituição educativa em sua dimensão interrelacional, dentro do contexto sociocultural em que esta se situa. Ele defende a valorização das histórias de vida desses agentes que se exercem de modo entrelaçado e com variados sentidos. Essas histórias constituem o cotidiano
17. O "Contos e Cantos ao Redor do Fogo" é um evento festivo que ocorre anualmente e já está inserido no calendário institucional da UECE. Sempre realizado no final de junho, esse evento culmina com o fim do semestre letivo e constitui-se de elementos da cultura popular através do conto de histórias, lendas, cantos, dança, teatro, instalações, exposições de artesanato etc. Ao longo dos anos, vem alcançando boa participação de pessoas da comunidade local e da própria Universidade. 
institucional, criando saberes-fazeres - para trazer o termo que Ferraço (2008) utiliza - e aprofundando os sentidos que cada um atribui a esse cotidiano.

A contribuição das ideias de Bourdieu $(1983,2004,2006)$ nas presentes reflexões são de grande relevância para se pensar os processos constitutivos dos currículos universitários e escolares por considerá-los imersos em uma dada realidade sócio histórica, sendo esta permeada por relações sociais de poder. Bourdieu $(1983,2004,2006)$ considera ainda que a atuação de diferentes agentes em inter-relação possibilita mudanças na sociedade, sejam elas nos valores e atitudes das pessoas, sejam nas estruturas institucionais e sociais mais amplas.

Priorizar o ensino de Arte requer dos professores formadores universitários - e escolares, muita discussão, luta coletiva e a compreensão de que a produção de conhecimento artístico tende a gerar a ampliação da criatividade, da sensibilidade estética, da atuação ética, crítica e propositiva. Quem vai dizer, com isso, que as artes não são importantes na formação humana e, principalmente, na formação profissional dos educadores?

Acredita-se que a arte pode permear as demais disciplinas além de ter um espaço disciplinar específico nos currículos. Para tanto, é necessário retomar o diálogo interdisciplinar tão em voga nos últimos anos, atrelando-o ao processo de formação e de prática docente.

É preciso, pois, ter consciência de que essas mudanças são muito difíceis e requerem muita energia científica, política, relacional e, principalmente, criativa. Mas, é importante também crer que essas mudanças são bastante possíveis e necessárias, pois como, acertadamente diz o poeta: $A$ arte existe porque viver não basta (Gullar, 2010).

\section{REFERÊNCIAS}

ANDES (2013). Proposta da Associação Nacional dos Docentes do Ensino Superior-SN para a Universidade Brasileira. Cadernos ANDES, 2 (4. ${ }^{a}$ edição). Sindicato Nacional dos Docentes das Instituições de Ensino Superior.

Barbosa, A. M. (1985). Arte-educação: conflitos e acertos. Max Limonad.

Barbosa, A. M. (2014). A imagem no ensino da arte. Perspectiva.

Bourdieu, P. (1983). Questões de sociologia. Marco Zero.

Bourdieu, P. (2004). Os Usos sociais da ciência: por uma sociologia clínica do campo científico. UNESP.

Bourdieu, P. (2006). A Produção da Crença: contribuição para uma economia dos bens simbólicos. Zouk.

Brasil (1971). Lei de Diretrizes e Bases da Educação Nacional n 5692/71. Brasília: Ministério da Educação.

Brasil (1996). Lei de Diretrizes e Bases da Educação Nacional, nº 9394/96. Brasília: Ministério da Educação.

Brasil (1997). Parâmetros Curriculares Nacionais: Artes. Brasília: Ministério da Educação.

Brasil (2006). Diretrizes Curriculares Nacionais para o Curso de Graduação em Pedagogia. Brasília: Conselho Nacional de Educação/Conselho Pleno.

Brasil (2008). Lei No 11.769, de 18 de agosto de 2008. Brasília: Ministério da Educação.

Brasil (2010). Diretrizes Curriculares Nacionais para a Educação Infantil. Brasília: Ministério da Educação/Secretaria da Educação Básica. 
Brasil (2012). Diretrizes Curriculares Nacionais para o Ensino Médio. Brasília: Ministério da Educação/Secretaria da Educação Básica.

Brasil (2015). Diretrizes Curriculares Nacionais para a Formação em Nível Superior. Brasília: Conselho Nacional de Educação/Conselho Pleno.

Brasil (2016). Lei No 13.278, de 2 de maio de 2016. Brasília: Ministério da Educação.

Brasil (2017). Base Nacional Comum Curricular: Ensino Médio. Brasília:

Ministério da Educação.

Brasil (2018). Base Nacional Comum Curricular. Brasília: Ministério da Educação.

Coelho, T. (2012). Dicionário crítico de política cultural. Iluminuras.

Duarte-Junior, J. F. (2010). A montanha e o videogame: escritos sobre educação. Papirus.

Ferraço, C. E. (Org.). (2008). Cotidiano escolar, formação de professores (as) e currículo. Cortez.

Gullar, F. (2010, agosto 9). 'A Arte existe porque a vida não basta', diz Ferreira Gullar. G1. http://g1.globo.com/pop-arte/flip/noticia/2010/08/arte-existeporque-vida-nao-basta-diz-ferreira-gullar.html.

Lopes, A. C., \& Macedo, E. (2011). Teorias de Currículo. Cortez.

Mairinque, I. M. (2003). Karl Popper e a teoria dos mundos de Platão.

Revista Eletrônica Metanoia, 5, 7-17. http://www.funrei.br/publicações/

Moraes, A. C. (2010). A defesa do ensino de Artes a partir das articulações entre o movimento de artistas e arte-educadores de Itapipoca-Ce. In F. J. F. Costa, A. C. Moraes, A. S. P. Xerez \& D. C. Lima (Orgs.), Vozes da FACEDI: Reflexões, experiências e perspectivas em educação (pp.20-35). EdUECE.

Moraes, A. C. (2016). Educação Estética na Universidade: Antropofagias e Repertórios Artístico-culturais de Estudantes. CRV/EdUECE.

Schiller, F. (1991). Cartas sobre a educação estética da humanidade. EPU.

Silva, T. T. (2007). Documentos de Identidade: uma introdução às teorias do currículo. Autêntica.

Suassuna, A. (1996). Iniciação à Estética. EdUFPE. 
Informação dos autores:

i Universidade Estadual do Ceará, Brasil. https://orcid.org/0000-0002-8650-8272

ii Universidade Estadual do Ceará, Brasil. https://orcid.org/0000-0001-5492-1671

iii Universidade Federal do Ceará, Brasil. https://orcid.org/0000-0002-1063-4811

Toda a correspondência relativa a este artigo deve ser enviada para:

Ana Cristina de Moraes

Rua Castro Meireles, 90 - casa 06. Bairro Mondubim. 60.711-475. Fortaleza-Ce, Brasil.

cris.moraes@uece.br

Recebido em 10 de novembro de 2019

Aceite para publicação em 6 de outubro de 2020 


\title{
The field of artistic knowledge in the training curriculum of pedagogues and its echo in schools
}

\begin{abstract}
In this article, we present a reflection on art as a field of legitimized knowledge (or not) for the training of teachers and the repercussion of this training in their future teaching activities with arts, in the initial series of Basic Education, and the relation of this training with is determined by the legal documents in the country. For this, we analysed the context of initial training in Pedagogy, briefly highlighting the evolution of the field of Art in the school curriculum in Brazil, focusing on aesthetic education. We also discuss what kind of knowledge in Arts is (or should be) proclaimed and exercised in the curricula and what is actually practiced in the curricula of the Pedagogy courses of the Universidade Estadual do Ceará UECE/Faculdade de Educação de Itapipoca FACEDI and the articulation of these curricula with the activities of research and extension existing in this institution. The results of our analysis point to the understanding that curriculum is not a mere prescription, but a set of possibilities that requires us to consider the diversity present in school every day, as a formative and interventional element.
\end{abstract}

Keywords: Initial training; Curriculum; Artistic knowledge. 


\section{El campo del saber artístico en los currículos de formación de pedagogos y su eco en las escuelas}

\section{RESUMEN}

En este artículo, presentamos una reflexión acerca del arte como campo de saber legítimo (o no) para la formación de profesores(as) pedagogos(as) y la repercusión de esa formación en sus futuras actividades docentes con artes, en las series iniciales de la Educación Básica, y la relación de esa formación con lo que determinan los documentos oficiales en el país. Para ello, analizamos el contexto de la formación inicial en Pedagogía, ubicando brevemente la evolución del campo del Arte en el currículo escolar en Brasil, con enfoque en la educación estética. Fue discutido también los saberes en artes que son (o deberían serlos) proclamados y ejercidos en los currículos y lo que, de hecho, se practica en los currículos de los cursos de Pedagogía de la Universidade Estadual do Ceará UECE/Faculdade de Educação de Itapipoca - FACEDI y la articulación de esos currículos con las actividades de investigación y extensión existentes en esa institución. Los resultados de los análisis señalan para la comprensión de que el currículo no es una simple prescripción, sino un conjunto de posibilidades que nos exige considerar la diversidad que hay en el cotidiano escolar como elemento formativo e intervencionista.

Palabras-clave: Formación inicial; Currículo; Saberes artísticos. 